Check for updates

Cite this as: $B M J 2021 ; 374: n 1685$ http://dx.doi.org/10.1136/bmi.n1685 Published: 02 July 2021

\title{
Covid-19: Long covid cases are underreported in GP records, research suggests
}

Jacqui Wise

GPs may be underreporting long covid say researchers who analysed 58 million patients' primary care records and found a much lower prevalence than previous survey estimates.

An analysis of pseudonymised electronic health records of patients in England found only 40 cases of long covid reported per 100 ooo people. ${ }^{1}$ This is a much lower prevalence than estimates using questionnaire research methods such as the React-2 study which estimated that around two million people have the condition. ${ }^{2}$

The analysis, published in the British Journal of General Practice, also found wide variation in reporting of long covid by GP practice, geographic region, and electronic notes systems doctors used.

Researchers found that up to 25 April 2021 there were only 23273 cases with a recorded diagnostic code indicative of a long covid diagnosis. Cases ranged from 20.3 per 100 ooo people in the east of England to 55.6 per 100 ooo in London. Rates were higher among women (52.1 per 100 ooo) than men (28.1 per 100 000).

Ben Goldacre, the lead researcher from the University of Oxford's Nuffield Department of Primary Care Health Sciences, said, "We were surprised to see almost a hundred fold difference in prevalence between population survey estimates and formally recorded diagnoses for the same condition.” He added, "Good data on long covid will be crucial for research into prevalence, its causes and consequences, and to plan services effectively."

Long covid is broadly defined as a continuation of the symptoms of covid-19 for more than four weeks with symptoms commonly including breathlessness, headaches, cough, fatigue, and "brain fog."

The study found that the rate of long covid recorded among practices using EMIS software was 53.7 per 100 ooo people compared with 20.9 per 1000000 in practices using TPP software. Over a quarter of GP practices $(26.7 \%)$ have not recorded any cases of long covid. The proportion is much higher in practices using TPP (44.2\%) than those using EMIS (15.1\%).

Part of the problem may be variable awareness of the new diagnostic codes that were launched in November 2020 and only available in EMIS at the end of January 2021. Symptoms between 4 to 12 weeks are defined as "ongoing symptomatic covid-19" and symptoms continuing beyond 12 weeks as "post-covid-19 syndrome" There are also three assessment codes and 10 referral codes relating to long covid. None of these codes explicitly contain the term "long covid," however.
The researchers called on NHS Digital to update the diagnostic codes to include the phrase "long covid" as "there is now a clear mismatch between formal clinical terminology and popular parlance among clinicians and patients." They also urged the National Institute for Health and Care Excellence and NHS England to communicate with doctors on the importance of correctly coding long covid in patients' records "as a high national priority."

As well as matters around recording of diagnoses, the researchers said there is a "strong possibility" that doctors are not currently diagnosing their patients as having long covid. This could be because patients are not presenting to their GP or because doctors are missing the diagnosis.

The study used the Open SAFELY platform which runs analyses across the full electronic health records of $96 \%$ of the English population. It was jointly funded by UK Research and Innovation, the National Institute for Health Research, Asthma UK-BLF, and the National Core Studies programme.

1 Walker A, MacKenna B, Inglesby P, et al. Clinical coding of long covid in English primary care: a federated analysis of 58 million patient records in situ using OpenSAFELY. British Journal of General Practice. https://bjgp.org/content/early/2021/06/28/BJGP.2021.0301.

2 O'Dowd A. Covid-19: Third of people infected have long term symptoms. BMJ 2021;373:n1626. doi: 10.1136/bmj.n1626 pmid: 34168002

This article is made freely available for use in accordance with BMJ's website terms and conditions for the duration of the covid-19 pandemic or until otherwise determined by BMJ. You may use, download and print the article for any lawful, non-commercial purpose (including text and data mining) provided that all copyright notices and trade marks are retained. 